Pengaruh Dukungan Sosial Terhadap Penyesuaian Diri pada

Mahasiswa Sumatera di UIN Sayyid Ali Rahmatullah

Proyeksi, Vol. 16 (2) 2021, 153-165

\title{
PENGARUH DUKUNGAN SOSIAL TERHADAP PENYESUAIAN DIRI PADA MAHASISWA SUMATERA DI UIN SAYYID ALI RAHMATULLAH
}

\author{
Asmalia Alnadi ${ }^{1}$ dan Citra Ayu Kumala Sari ${ }^{2}$ \\ ${ }^{1,2}$ Fakultas Ushuluddin, Adab, dan Dakwah \\ Universitas Islam Negeri Sayyid Ali Rahmatullah, Tulungagung \\ E-mail: asmaliaalnadi26@gmail.com, citraayukumalasari@gmail.com
}

\begin{abstract}
Abstrak
Mahasiswa rantau menghadapi berbagai permasalahan dalam proses menempuh pendidikannya. Permasalahan yang dihadapi mahasiswa rantau ini karena terdapat masalah dalam penyesuaian diri. Penelitian ini bertujuan adalah mengetahuipengaruhdukungan sosial terhadap penyesuaian diri pada mahasiswa diSumatera UIN Sayyid Ali Rahmatullah. Jenis penelitian ini kuantitatif kausual komparatif dengan analisis regresi. Sampel yang digunakan sebanyak 162 responden dengan menggunakan random sampling. Metode pengumpulan data dalam penelitian ini menggunakan skala dukungan sosial dan skala penyesuaian diri, serta untuk uji hipotesis menggunakan regresi sederhana. Diperoleh hasil nilai signifikansi sebesar $0,000<0,05$. Dengan nilai koefisien regresi sebesar 0,969 dan nilai $\mathrm{R}^{2}$ sebesar 0,558 sama dengan $55,8 \%$. Sehingga hasil penelitian ini menyatakan bahwa dukungan sosial berperan signifikan terhadap penyesuaian diri pada mahasiswa di SumateraUIN Sayyid Ali Rahmatullah. Artinya jika dukungan sosial yang didapatkan tinggi, maka penyesuaian diri pada mahasiswa Sumatera juga akan tinggi.
\end{abstract}

Kata Kunci: UIN Sayyid Ali Rahmatullah, Penyesuaian Diri, Dukungan Sosial

\section{THE EFFECT OF SOCIAL SUPPORT TOWARDS SELF-ADJUSTMENT AMONG SUMATERANS STUDENTS IN UIN SAYYID ALI RAHMATULLAH}

\begin{abstract}
Wender students face various problems in the process of taking their education. The problems faced by overseas students are because there are problems in adjustment. This study aims to determine the effect of social support on self-adjustment in Sumatera students of UIN Sayyid Ali Rahmatullah. This type of research is quantitative causal comparative with regression analysis. The sample used was 162 respondents using random sampling. The data collection method in this study used a social support scale and a self-adjustment scale, and to test the hypothesis using simple regression. The results obtained a significance value of $0.000<0.05$. With a regression coefficient value of 0.969 and an $R 2$ value of 0.558 , it is equal to $55.8 \%$. The results of this study state that social support plays a significant role in adjustment to Sumatera students at UIN Sayyid Ali Rahmatullah. This means that if the social support obtained is high, then the adjustment of Sumatera students will also be high. Keywords: Sayyid Ali Rahmatullah State Islamic University, Adjustment, Social Support
\end{abstract}

\section{Pendahuluan}

Menurut data dari Kementerian Riset dan Teknologi Republik Indonesia dari total 8.043.480 mahasiswa yang menyebar diseluruh Indonesia dan pulau Jawa meduduki urutan pertama mahasiswa terbanyak (Kementerian Riset Teknologi dan Pendidikan Tinggi Indonesia, 2018). Mahasiswa rantau adalah pelajar yang menuntut ilmu di perguruantinggi diluar dari daerah asalnya(Lingga \& 
Tuapattinaja, 2012). Terdapat perbedaan yang ditemukan saat individu pindahan dari tempat tinggal ke daerah lain sepertibahasa, kultur budaya, kondisi tempat tinggal serta perubahan lingkungan (Marta, 2014). Santrock (2012) menyatakan mahasiswa yang mengalami masa peralihan dari masa sekolah menengah atas menuju masa perguruan tinggi akan melibatkan banyak struktur besar dan interpersonal seperti berinteraksi dengan teman baru dan meningkatkan asesmennya. Karena menjadi mahsiswa secara tidak langsung harus bisa beradaptasi. Saat pertama kuliah, mahasiswa akan merasakan perubahan dari hidupnya yang akan mengakibatkan tingkat stres yang tinggi (Conley, Travers, \& Bryant, 2013). Thurber dan Walto (2012) juga berpendapat bahwa mahasiswa rantau baruakan merasakan homesick, yakni adanya rasa tidaknyaman ketika harus meninggalkan rumah. Menurut Heiman dan Kariv (2005) mahasiswa dituntut untuk menyesuaikan diri terhadap tekanan untuk naik kelas, lama belajar, kecemasan menghadapi ujian, banyaknya tugas yang harus diselesaikan, dan manajemen waktu.

Fenomena mahasiswa perantau pada dasarnya bertujuan untuk memperoleh kesuksesan lebih baik sesuai dengan bidang yang diharapkan. Fenomena dianggap sebagai suatu usaha untuk membuktikan kualitas dari diri individu dan dapat bertanggung jawab dalam membuat keputusan (Santrock, 2002). Hal ini didukung dengan penelitian yang dilakukan oleh Aprianti (2012) didalam penelitiannya memperlihatkan bahwa mahasiswa rantau di tahun pertama Universitas Indonesia memiliki dukungan sosial yang bagus maka dari itu tingkat kesejahteraan psikologisnya akan tinggi pula, penelitian ini dilakukan pada 131 mahasiswa rantau. Halim dan Dariyono (2016) mengungkapkan bahwa mayoritas mahasiswa rantau merasakan kesepian. Maka dari itu peran dan dukungan dari orang lain dalam penyesuaian diri ini sangat diperlukan, dukungan ini biasa disebut dukungan sosial, Schneiders (1964). Sesuai dengan Sarafino (2008) mengatakan dukungan sosial mengacu kepada rasa nyaman, perhatian, harga diri, atau berupa bantuan kapada orang lain atau kelompok kepada individu tersebut. Aspek dukungan sosial meliputidukungan emosional, dukungan instrumental, dukungan informasi, dan dukungan penghargaan (Sarafino, 2008). Menurut Riena (2010) seperti keintiman, harga diri, keterampilan sosial. Seperti yang dikemukakan oleh King (2012) bahwa dukungan sosial merupakaninformasi yang berasal luar individu tersebut yang meperlihatkan bahwa orang lainmenunjukkan rasa cinta dan diperhatikan, menghargai, dihormati, dan ikut sertakan dalam segala komunikasi dan kewajiban berhubungan dan bersifat berbalas. Selain itu Santrock (2006) menjelaskan bahwa dukungan sosial adalah memperoleh informasi atau kritik, komentar dan sebagainya dari orang lain yang dianggap sangat penting dalam hidup individu nya yang saling bergantung satu sama lain. Ada juga menurut Baron dan Byrne (2003) yang mengatakan bahwa dukungan sosial adalah kenyaman jasmani dan psikologis yang diperoleh individu dari teman, keluarga dan orang sekitarnya.

Hasil penelitian Rufaida dan Kustanti (2018) menyebutkan bahwa dukungan sosial teman sebaya rendah akan menyebabkan penyesuaian diri nya juga akan rendah. Pada umumnya penyesuaian diri akan mengkaitkan seseorang dengan keadaan lingkungan sekitarnya, penyesuaian diri berkaitan dengan tingkah laku dan mental sehingga membuat individu akan berupaya menangani semua kebutuhannya mulai dari tekanan, frustasi, dan permasalahan batin serta menyeimbangkan tututan yang diberikan kepada individu oleh dunia yang menjadi tempat tinggalnya.Dalam penelitian yang dilakukan Saniskoro dan Akmal (2017), menguraikan hasil penelitiannya bahwa penyesuaian diri berpengaruh dalam proses menurunkan tingkat stres akademik mahasiswa yang menunjukkan bahwa pelajar akan bisa menyesuaian diri dengan lingkungan perkuliahan maka secara tidak langsung akan menurunkan stres akademik yang dialami pelajar.Pada umumnya penyesuaian diri akan mengkaitkan 
seseorang dengan keadaan lingkungan sekitarnya, penyesuaian diri berkaitan dengan tingkah laku dan mental sehingga membuat individu akan berupaya menangani semua kebutuhannya mulai dari tekanan, frustasi, dan permasalahan batin serta menyeimbangkan tututan yang diberikan kepada individu oleh dunia yang menjadi tempat tinggalnya (Yustinus, 2006).

Menurut studi kasusyang dilakukan oleh mahasiwa Sumatera di UIN Sayyid Ali Rahmatullah diperoleh kesimpulan terdapat pemasalahan yang dihadapi mahasiswa rantau di dalam proses penyesuaian diri mereka. Kerena mereka merasakan perbedaan dari tempat tinggal mereka sebelumnya. Harus tinggal dilingkungan baru yang sebelumnya tidak pernah didatangi. Bertemu dengan teman yang baru dengan karakter mereka yang beragam dan belum saling mengenal. Belum lagi dengan tuntutan mereka yaitu harusmereka jalani yaitu menempuh pendidikan sebagai tujuan utama mereka. Dengan adanya dukungan yang mereka dapatkan dari teman dan orang disekitar membuat mahasiswa perantau ini merasakan rasa nyaman dan mulai bisa berbaur dengan lingkungan baru mereka, sehingga dukungan ini memiliki pengaruh yang sangat besar dalam penyesuaian diri mahasiswa rantau. Mahasiswa rantau disini membutuhkan rasa diterima oleh orang baru ditempat tinggalnya. Dukungan yang sangat berpengaruh disini dukungan dari teman mereka karena selama mahasiswa ini merantau kehidupan mereka selama merantau dihabiskan bersama teman.

Kebanyakan para remaja masih tinggal bersama dengan orang tuanya, pada saat merantau sosok orang tua sangat berpengaruhuntuk membantu remaja memahami lingkungan sosialnya, serta memahami tanggung jawabyang diberikankepada mereka dan dapat menyesuaiakan diri (Maharani \& Andayani, 2003). Penyesuaian diri menurut Enung (2008) adalah bagian darisesuatu sistem alamiah dan fleksibel yang bergunauntuk merubah perilaku individu tersebut, agar nantinyaterbentuk suatu hubungan yang sama dengan keadaan lingkungan. Adapun aspek dari penyesuaian diri adalah penyesuaian diri pribadi dan penyesuaian diri umum (Enung,2008). Menurut Schneider (1964) faktor yang memengaruhi penyusaian diri yakni keadaan fisik, perkembangan dan kematangan, suasana lingkungan sekitar, kondisi pikologis,derajat keimanan dan budaya. Adapun pendapat yang menyatakan bahwa penyesuaian diri merupakan bagian dari proses seseorang dalam bergaul dengan lingkungannya atau sebaliknya dengan merubah keadaan lingkungan menjadi sesuai dengan yang diharapkan individu tersebut (Walgito, 2003). Sedangkan Schneiders (1964) menjelaskan penyesuaian diri sebagai prosesdidalam nya terdapattanggapan mental dan perilaku yang memperjuangkan oleh individu bisa berhasil untuk memenuhi kebutuhan diri nya, permasalahan, stres dan keseimbangan antara individu dengan lingkungan yang berbeda. Sehingga berdasarkan pemaparan diatas mengatakan bahwa budaya mempengaruhi penyesuaian diri individu hal ini disebabkan karena individu tersebut baru mengenal budaya tersebut sehingga merasa asing bahkan tidak nyaman. Ada juga faktor lain yang mempengaruhi penyesuaian diri seperti keadaan fisik, keadaan psikologis, perkembangan dan kematangan dan dukungan sosial. Tetapi pada penelitian ini peneliti memilih variabel dukungan sosial yang mempengaruhi penyesuaian diri karena variabel tersebut akan mengulas seberapa berpengaruhnya orang di lingkungan nya.

Penelitian oleh Khoyroh (2016) mengatakanaadanya pengaruh antara pengungkapan diri dan penyesuaian diri mahasiswa. Selain itu penelitian lain dilakukan Lestari (2016) dimana di dalam penelitiannya menjelaskan bahwa terdapat pengaruh antara pengungkapan diri dan penyesuaian diri. Penyusaian diri yang dimaksud ialah sikap baik hati kepada orang lain, ikut serta dan bisa melakukan tugas sebagaimana harusnya (Gunarsa, 2008). Selain itu, penelitian yang dilakukan oleh Trianni (2013) yang menunjukakan adanya hubungan dari dukungan keluarga dengan kepatuhan berobat pada 
penderita hipertensi di Puskesmas Ngaliyan Semarang. Selanjutnya penelitian oleh Aristya dan Rahayu (2018), hasil dalam penelitianya bahwa mempunyai hubungan yang penting dari dukungan sosial dan penyesuaian diri di kalangan SMA.

Dari pemaparan diatas, peneliti tidak menemukan penelitian yang membahas tentang dukungan sosial terhadap penyesuaian diri pada mahasiswa Sumatera. Selain itu, penelitian mengenai penyesuaian diri juga tidak ditemukan subjek mahasiswa Sumatera di UIN Sayyid Ali Rahmatullah Tulungagung sebagai subjek atau responden dalam penelitian. Perbedaan dari penelitian ini dengan yang subjek yang diteliti dan tempat yang diteliti. Sehingga peneliti tertarik melakukan penelitian yang bermaksud untuk melihat adakah pengaruh dari dukungan sosial terhadap penyesuaian diri mahasiswa Sumatera di UIN Sayyid Ali Rahmatullah. Adapun rumusan masalah dalam penelitian ini apakah dukungan sosial berpengaruh terhadap penyesuaian diri pada mahasiswa Sumatera UIN Sayyid Ali Rahmatullah. Sedangkan untuk hipotesis peneliti mengambil adanya pengaruh dukungan sosial terhadap penyesuaian diri pada mahasiswa Sumatera di UIN Sayyid Ali Rahmatullah. Dalam penelitian ini diharapkan akan mengetahui bagaimana pengaruh dukungan sosial terhadap penyesuaian diri mahasiswa Sumatera diUIN Sayyid Ali Rahmatullah.

\section{Metode}

Pada penelitian ini peneliti menggunakan metode penelitian kuantitatif. Jenis penelitian yang dipakai adalah kasual komperatife, dengan analisis regresi. Populasi dari penelitian ini adalah mahasiswa Sumatera di UIN Sayyid Ali Rahmatullah sebanyak 300 mahasiswa yang bersumber dari data yang dimiliki ketua forum mahasiswa Sumatera UIN Sayyid AliRahmatullah. Teknik sampling yang dipakai peneliti dalam penelitian adalah random sampling. Sampel yang digunakan dalam penelitian ini adalah 162 mahasiswa dari Sumatera, yang ada di UIN Sayyid Ali Rahmatullah. Kriteria dalam penelitian ini adalah mahasiswa aktif dan mahasiswa yang berasal dari Sumatera yang menempuh pendidikan di UIN Sayyid Ali Rahmatulah. Pengambilan data ini memakai skala psikologi yang dikembangkan peneliti dan selanjutnya akan diuji kualitas psikometri baik dengan menggunakan validitas ataupun reliabilitas.

Penelitian ini memakai dua buah skala yang terdiri dari skala dukungan sosial yang terdiri dari 22 aitem atau soal yang merujuk pada teori Sarafino (2006), sedangkan skala penyesuaian diri yang terdiri dari 30 aitem atau soal yang merujuk pada teori Enung (2008). Dengan tahap awal menentukan teori yang sesuai, dilanjutkan dengan dimensi dan pembuatan indikator tiap dimensi. Selanjutnya dengan membuat kuesioner. Skala pengukuran yang digunakan yang digunakan keduanya menggunakan 4 pilihan jawaban yaitu STS (sangat tidak setuju), TS (tidak setuju), S (setuju), SS (sangat setuju). Sedangkan untuk uji validasi isi dinilai oleh tujuh expert judgement. Adapun kriteria expert judgment yang dilibatkan dalam penelitian ini adalah yang menguasai bidang psikologi dan faham atau menguasai akan penelitian kuantitatif. Setelah itu, hasil penilaian tersebut diolah dengan menggunakan Aiken's $V$ dengan indeks $V=0.75$. Didalam aitem-aitem dukungan sosial memiliki nilai Aken's $V$ yang bergerak dari nilai 0,75 hingga 0,86 . Sedangkan didalam aitem-aitem pada skala penyesuaian diri memiliki nilai Aiken's $V$ yang bergerak dari nilai 0,75 hingga 0,93 .

Uji coba aitem ini dilakukan pada 41 subjek yang berbeda dari sampel yang nantinya akan digunakan. Setelah itu dilakukan uji seleksi aitem dengan mengkorelasikan skor total dengan menggunakan teknik korelasi pearson product moment. Hasil dari uji reliabilitas pada skala dukungan sosial terdapat sebanyak 22 aitem atau soal yang valid atau sahih dan di skala penyesuaian diri terdapat 
sebanyak 30 aitem yang valid atau sahih. Batasan dari penelitian ini menggunakan $r_{i x} \geq 0,30$. Berdasarkan yang dikemukakan oleh Azwar (1994) Jika terkandung aitem yang memiliki indeks daya diskriminasi mirip atau lebih berasal dari 0,30 dan jumlahnya telah melebihi kuantitas aitem yang direncanakan pada mulanya untuk dijadikan skala, maka peneliti dapat memilih aitem yang memiliki indeks daya diskriminasi tinggi. Maka berdasarkan pernyataan tersebus beroleh 22 aitem dengan kisaran aitem sahih $(0,30-0,706)$ pada skala dukungan sosial dan 30 aitem dengan kisaran aitrm sahih $(0,30-0,701)$ pada skala penyesuaian diri. Sementara itu, uji reliabitias dengan Cronbach's Alpha menghasilkan nilai koefisien reliabilitas sebesar 0,883 dari skala dukungan sosial dan 0,909 dari skala penyesuaian diri.

Analisi data statistik yang digunakan untuk menguji hipotesis penelitian ini yakni teknik analisis regresia sederhana. Uji asumsi klasik menggunakan uji normalitas, uji linieritas dan uji heteroskedastisitas. Sementara itu, untuk uji hipotesis menggunakan perhitungan statistik dengan menggunakan bantuan SPSS v.23 for windows.

Hasil

Gambar demografis partisipan di dalam penelitian ini dikategorikan berdasarkan dari jenis kelamin. Seperti yang terterapada tabel 1 dibawah ini.

Tabel 1. Kategorian partisipandari jenis kelamin

\begin{tabular}{cccc}
\hline No. & Jenis Kelamin & Jumlah & Presentase \\
\hline 1. & Laki-laki & 42 & $26 \%$ \\
2. & Perempuan & 120 & $74 \%$ \\
\hline
\end{tabular}

Pada tabel diatas menunjukan bawah terdapat 42 responden laki-laki dengan presentase sebesar $26 \%$ dan 120 responden dengan presentase sebesar $74 \%$. Berdasarkan data hipotetik dan data empiris dari 162 partisipan peneliti membuat gambaran statistik, bedasarkan dari variabel dukungan sosial dan variabel penyesuaian diri. Seperti ditujukkan pada tabel 2.

Tabel 2. Data Hipotetik dan data empiris

\begin{tabular}{|c|c|c|c|c|c|c|c|c|c|}
\hline \multirow{3}{*}{ Variabel } & \multirow{3}{*}{$\mathbf{N}$} & \multicolumn{4}{|c|}{ Data Hipotetik } & \multicolumn{4}{|c|}{ Data Empiris } \\
\hline & & \multicolumn{3}{|c|}{ Skor } & \multirow[b]{2}{*}{ SD } & \multirow[b]{2}{*}{ Mean } & \multicolumn{2}{|c|}{ Skor } & \multirow[b]{2}{*}{ SD } \\
\hline & & Mean & Min & Max & & & Min & Max & \\
\hline Dukungan Sosial & 162 & 33 & 22 & 88 & 5,5 & 70 & 34 & 88 & 8 \\
\hline Penyesuaian Diri & 162 & 75 & 30 & 120 & 15 & 94 & 51 & 120 & 11 \\
\hline
\end{tabular}

Untuk melihat perbedaan dari masing-masing skor variabel, maka peneliti melakukan analisis kategori yang telah ditetapkan. Hasil analisis ini untuk melihat dukungan sosial dan penyesuaian diri pada mahasiswa Sumatera $(\mathrm{N}=162)$ seperti yang tertera pada tabel 3 dan tabel 4 . 
Tabel 3. kategorisasi Dukungan Sosial

\begin{tabular}{lcc}
\multicolumn{3}{c}{ Data Hipotetik } \\
\hline \multicolumn{1}{c}{ Kategori } & $\mathbf{F}$ & $\%$ \\
\hline Sangat Rendah & 0 & $0 \%$ \\
Rendah & 0 & $0 \%$ \\
Sedang & 1 & $0,6 \%$ \\
Tinggi & 0 & $0 \%$ \\
Sangat Tinggi & 161 & $99,4 \%$ \\
\hline
\end{tabular}

Berdasarkan pada tabel kategorisasi diatas, terdapat 1 mahasiswa atau 0,6\% yang memiliki dukungan sosial sedang, 161 mahasiswa atau sekitar 99,4\% yang memiliki dukungan sosial sangat tinggi. Lebih lanjut, peneliti juga mengelompokkan subjek pada lima kategori tingkatan pada penyesuaian diri. Seperti yang ditunjukanterhadap tabel 4 berikut.

Tabel 4. Kategori Penyesuaian Diri

\begin{tabular}{ccc}
\multicolumn{3}{c}{ Data Hipotetik } \\
\hline Kategorisasi & F & $\%$ \\
\hline Sangat Rendah & 1 & 0,6 \\
Rendah & 0 & $0 \%$ \\
Sedang & 18 & $11 \%$ \\
Tinggi & 97 & $60 \%$ \\
Sangat Tinggi & 46 & $28 \%$ \\
\hline
\end{tabular}

Berdasarkan pada tabel katergori diatas dapat dilihat, terdapat 1 mahasiswa atau sekitar 0,6\% memiliki penyesuaian diri sangat rendah,18 mahasiswa atau sekitar $11 \%$ yang memiliki penyesuaian diri sedang, dan 97 mahasiswa atau sekitar $60 \%$ yang memiliki penyesuaian diri tinggi, dan memiliki 46 mahasiswa atau sekitar $28 \%$ yang memiliki penyesuaian diri sangat tinggi. Lebih lanjut peneliti melakukan uji normalitas, sebagaimana ditampilkan pada tabel 5 .

Tabel 5. Hasil Uji Normalitas

\begin{tabular}{ll}
\hline & Unstandardized Residual \\
\hline Kolomogorov-Smirnov &, 052 \\
\hline
\end{tabular}

Peneliti melakukan uji normalitas menggunakan Kolmogorov-Smirnov yang memiliki standar koefisien senilai $p>0,05$. Didapatkan nilai signifikasi residual regresi sebesar $0,052(p>0,05)$. Sehingga berdasarkan data berikut mampu disimpulkan bahwa asumsi normalitasdari variabel dukungan sosial 
dan variabel penyesuaian diri terpenuhi dan berarti bahwa kedua variabel berdistribusi normal. Untuk lebuh lanjut, peneliti melakukan uji normalitas, seperti yang di tampilkan di tabel 6.

Tabel 6.Uji Linieritas

\begin{tabular}{lccccc}
\hline \multicolumn{7}{c}{ ANOVA Table } \\
\hline & Sum of Square & Df & Mean Square & $F$ & Sig. \\
Deviation from Linearity & 1519,152 & 36 & 42,199 &, 807 &, 769 \\
\hline
\end{tabular}

Dari hasil uji linieritas menunjukkan baik dari dukungan sosial atau penyesuaian diri diperoleh Deviation from Linearity sebesar 0,769 ( $p>0,05)$. Maka bisa ditarik kesimpulan bahwa ada hubungan linier dari dukungan sosial dan penyesuaian diri. Untuk melihat bagaimanaterjadinya heteroskedestisitas bisa dilihat pada gambar scatterplot berikut ini.

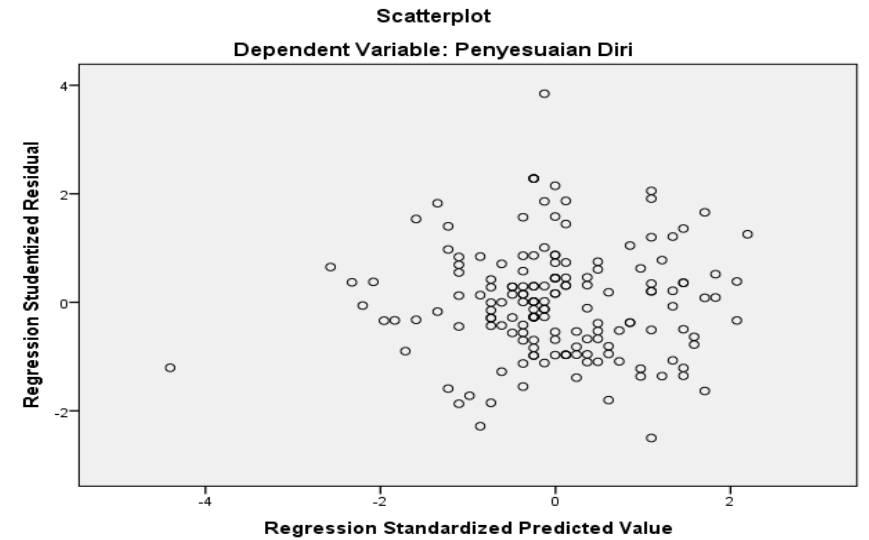

Gambar 1. Gambar Scatterplot

Pada gambar scatteplot diatasmenunjukan bahwa titi-titik tersebut berpencar secara acak serta menyebarmulai dari atas maupun bawah dari angka 0 dan sumbu Y. Maka dari itu dapat disimpulkan tidak terjadi heteroskedastisitas di model regresi. Untuk lebih lanjut peneliti melakukan uji hipotesis regresi sederhana untuk melihat adakah pengaruh dukungan sosial terhadap penyesuaian diri. seperti yang di tampilkan pada tabel 7 dibawah ini.

Tabel 7. Uji Hipotesis

\begin{tabular}{ccccc}
\hline & $\begin{array}{c}\text { Unstandardazid } \\
\text { Coefficients } \\
\text { (B) }\end{array}$ & $\begin{array}{c}\text { Standardized } \\
\text { Coefficients }\end{array}$ & t & Sig \\
\hline (Constant) & 26,034 &, 747 & 5,421 &, 000 \\
$\begin{array}{c}\text { Dukungan } \\
\text { sosial }\end{array}$ &, 969 & 14,224 &, 000 \\
\hline
\end{tabular}

Diperoleh hasil konstanta variabel dukungan sosial 26,034 sedangkan berdasarkan koefisien regresi variabel penyesuaian diri 0,969. Berdasarkan data tersebut di dapatkan persamaan regresi sederhana $Y=26,034 \beta+0,969 X$. Berdasarkan analisis regresi diketahui nilai Sig. 0.000 yang ditandai dengan $p<0,05$, jadi hipotesis nol $\left(H_{0}\right)$ ditolak dan hipotesis alternatif $\left(H_{a}\right)$ diterima. Sehingga kesimpulannya adalah terdapat pengaruh yang signifikan antara dukungan sosial terhadap penyesuaian diri pada mahasiswa Sumatera di UIN Sayyid Ali RahmatullahTulungagung. Berikutnya kita dapat melihat hasil dari uji koefisisen determinasi di tabel 8 dibawah ini. 
Tabel 8. Uji Koefisien Determinasi

\begin{tabular}{ccc}
\hline \multicolumn{3}{c}{ Model Summary $^{\mathbf{b}}$} \\
\hline Model & $\mathrm{R}$ & $\mathrm{R}$ Square \\
\hline 1 &, 747 &, 558 \\
\hline
\end{tabular}

Berdasarkan dari data tabel diatas dapat kita lihat bahwa hasil perhitungan $\mathrm{R}=0,747$ dan $R^{2}=0,558$. Artinya dukungan sosial berperan terhadap penyesuaian diri sebesar $55,8 \%$ dan sisanya dipengaruhi oleh variabel lain yang tidak termasuk dalam penelitian ini. Jadi dari analisis yang dilakukan bisa disimpulkan bahwa dukungan sosial berperan signifikan dan berpengaruh positif terhadap penyesuaian diri pada mahasiswa Sumatera di UIN Sayyid Ali Rahmatullah.

\section{Pembahasan}

Berdasarkan hasil penelitian yang diperoleh melalui tabel 4. Kategori Penyesuaian Diri pada kolom hipotetik, diketahui bahwa jumlah subjek pada penelitian ini terdiri dari 162 orang. Dari keseluruhan subjek penelitian ini terdapat $28 \%$ atau sejumlah 46 mahasiswa yang memiliki tingkat penyesuaian diri "sangat tinggi", selain itu terdapat $60 \%$ atau sejumlah 97 mahasiswa yang memiliki tingkat penyesuaian diri "tinggi", terdapat $11 \%$ atau sejumlah 18 mahasiswa yang memiliki tingkat penyesuaian diri "sedang", kemudian terdapat $0 \%$ atau tidak ada mahasiswa yang memiliki tingkat penyesuaian diri "rendah", dan yang terakhir terdapat 0,6\% atau sejumlah 1 mahasiswa yang memiliki tingkat penyesuaian diri "sangat rendah".

Berdasarkan pada deskripsi data dapat ditarik kesimpulan bahwa subjek penelitian ini memiliki penyesuaian diri ada pada golongantinggi. Maka dari itu secara umum, mahasiswa memiliki penyesuaian diri diatas rata-rata. Artinya satu individu dengan lainnya merasakan pengalamansama,mengakibatkan adanya perubahan dalam pendirian, kemampuan dan nilai individu, termasuk dalam penyesuaian dirinya. Oleh kerenaini penyesuaian diri membuat individu akan merubah dirinya sesuai dengan kondisi lingkungannya, tetapi individu juga dapat merubah lingkungan nya sesuai keadaan atau keinginan diri individu tersebut (Gerungan,2004). Selama perjalan pendewasaan untuk meraih kesuksesan, mahasiswa rantau mengalamibanyaknya perubahansertaselisihdalamsudut pandang kehidupanyang memperlihatkan penyesuaian dirinya (Chandra, 2004).

Dari penelitian ini diperoleh hasil perhitungan $R=0,747$ dan $R^{2}=0,558$, artinya dukungan sosial berperan terhadap penyesuaian diri sebesar $55,8 \%$. Hal ini dikuatkan dengan penelitian yang dilakukan oleh Kumalasari dan Ahyani (2012) dalam penelitian ini menyebutkan bahwa terdapat hubungan antara dukungan sosial dengan penyesuaian diri remaja di panti asuhan. Hal sesuai dengan penelitian Tricahyani dan Widiasavitri (2016) menjelaskan bahwa terdapat peningkatan berasal dari nilai dukungan sosial mengakibatkan peningkatan pula pada nilai penyesuaian diri. Kondisi ini cukup ideal karena terdapat $99,4 \%$ mahasiswa yang menunjukan pada kategori sangat tinggi. Kelompok mahasiswa rantau ini bisa memberikan contoh kepada yang lainnya agar dapat memiliki penyesuaian diri yang tinggi. Seperti menurut Walgito (1994) penilaian positif seseorang terhadap kondisi fisik seseorang berpengaruh dalam proses perkembangan sikap penerimaan diri kearah yang positip. Sedangkan terdapat 0,6 \% yang memiliki penyesuaian diri sangat rendah. Banyak individu yang memiliki rasatidak nyaman dengan suasana lingkungan baru dikarena ketidak mampuan individu dalam menyesuaikan diri, baik dalam lingkungan keluarga atau lingkungan sekolah (Hidayat \& Handayani, 2018).

Hal ini didukung oleh Kusrini dan Prihartani (2014) keuntungan dari dukungan sosial dari orang terpercaya akan menimbulkan rasa dirinya dilihat oleh orang lain, dihormati, memperoleh kasih 
sayang.Selanjutnya penelitian yang dilakukan oleh Wijaya (2015) memperlihatkanadanyakaitan antara penyesuaian diri dan kemandirian. ketika individu bisa menyesuaiakan diri di lingkungan baru nanti akan berdampak padakecakapan dalam berkomunikasi yang bagus, bisa hidup walaupun jauh dari orang tua, memperoleh pertemanan yang sehat, mudah berbaur dengan orang sekitar. Dari penelitian yang dilaksanakan Wijaya (2015) memperlihatkan bahwa penyesuaian diri yang dirasakan oleh mahasiswa rantau sangat tidak gampang. Hal ini juga terlihat didalam penelitian ini mahasiswa Sumatera yang sudah cukup lama memempuh pendidikan di UIN Sayyid ali rahmatullah mulai mudah menyesuaikan diri dengan keadaan disekitar mereka.

Bedasarkan dari penelitian 162 subjek terdapat 1 mahasiswa atau 0,6\% yang memiliki dukungan sosial sedang, 161 mahasiswa atau sekitar 99,4\% yang memiliki dukungan sosial sangat tinggi. Temuan ini menunjukkan kalau sebagian besar subjek memiliki dukungan sosial sangat tinggi, yang ditandai dapat tinggal dilingkungan baru, dapat menyelesaikan masalahnya sendiri, dapat menyelesaikan pendidikannya, sehingga pentingnya menumbuhkan kesadaran dalam diri individu tersebut agar bisa beradaptasi dengan lingkungan sekitarnya. Kondisi ini belum dikatakan ideal karena masiha ada 0,6 yang memiliki dukungan sosial nya sedang. Karena ketika individu mengalami stres yang rendah bukan berarti individu tersebut memperoleh dukungan sosial yang tinggi, tetapi hal tersebut dapat membantu mengurangi stres dengan lebih baik dibandikan dengan individu yang dukungan sosial nya rendah ( Adawiyah, 2013).

Penelitian yang dilakukan Lee dan Ybarra (2017) menjelaskan pandanganyang berbeda mengenai dukungan sosial, dimana individu akan mendapatkan dukungan sosial tergantung individu akan melakukan nya dengan siapa. Seperti penelitian yang dilakukan Sharma (2012) bahwa mahasiswa di tahun awal akan memperoleh masalah emosional setelah ia memasuki perguruan tinggi, ini disebabkan banyaknya tekanan yang tidak terduga, yang membuat mahasiswa pada tahun pertama emosionalnya akan turun, seperti kecemasannya terhadap lingkungan baru. Penelitian ini mendukung pernyataan Rahmat (2005) mengatakanhidup bermasyarakat berpengaruh kepada bentuk dari penyesuaian diri sesorang tersebut, penyesuaian sosial berlaku ketika seseorang dapat hidup dan menyesuaiakan diri bersama orang disekitar lingkungannya.

Berikut inimerupakan bukti kalau penyesuaian diri berhubungan dengan dukungan sosial. Friedlander, dkk (2007) memaparkan walaupun menaikkan dukungan sosial yang diperolah dari teman tetapi dari keluarga tidak, bisamemperkirakan penyesuaian diri di individu tersebut. Seperti dalam penelitian ini masih terdapat $0,6 \%$ atau 1 partisipan yang memiliki penyesuaian diri sangat redah. Sedangkan $R^{2}$ senilai 0,558 atau sebesar $55,8 \%$ dukungan sosial berperan dalam penyesuaian diri pada mahasiswa rantau. Yang terlihat juga pada gambar Scatterplot bahwa titik titinya menyebar mulai dari bagian atas ataupun bawah.

Berdasarkan dari hasil uji hipotesis memperlihatkan bahwa adanya dukungan sosial berperan signifikan dan positif terhadap penyesuaian diri pada mahasiswa Sumatera UIN Sayyid Ali Rahmatullah. Dengan didapatkan nilai Sig. 0,000 atau $p<0,05$ dengan nilai kostanta $\beta$ 26,034 dan koefisien regresi penyesuaian diri 0,969. Hal ini dikuatkan dengan penelitian Tazakhrofatin (2018), didalam penelitiannya memperoleh hasil hipotesis hal ini ditunjukkan adanya penyesuaian santri yang dipengaruhi oleh dukungan sosial dan orientasi masa depan. Berdasarkan dari teori yang diungkapkan oleh (Wills, 2005) yang mengartikan penyesuaian diriketika individu dapat hidup dan bergaul dengan lingkungannya secara wajar, sehingga didalam diri individu merasa puas kepada dirinya dan lingkungan. Hal ini sejalan dengan penelitian ini yang hanya terapat $0,6 \%$ atau setara dengan 1 
partisipan yang memiliki penyesuaian diri nya sangat rendah, yang artinya sisanya dapat beradaptasi dengan lingkungannya berjalannya waktu.

Dengan nilai sumbangan dukungan sosial kepada penyeusuaian diri senilai $55,8 \%$, padahal sisanya penyesuaian diri dipengaruhi oleh segi lain yang tidak masuk dalam penelitian ini. Secara teoritis banyak faktor yang mempengaruhi penyesuaian diri seperti kondisi fisik (keterunan, kesehatan, dan kondisi mental), perkembangan dan kematangan (IQ, moral, sosial dan emosi), situasi psikologis (pengalaman, pembiasaan, frustasi dan perselisihan), situasi lingkungan seperti (lingkungan rumah, sekolah, keluarga dan masyarakat), dan segi budaya termasuk agama. Agama dapat menjadi energi positif untuk pribadi yang sehat fisik dan sehat secara mental (Utami, 2012). Selain dukungan sosial ada faktor lain yang mempengaruhi tercapainya penyesuaian diri mahasiswa, salah satunya strategi coping. Hal ini sesuai dengan pernyataan Lazarus, Folkman, Cohen tentang coping yang merupakan cara yang dibutuhhkan individu untuk mencoba mengaturwaktu dari tanggung jawab yang dimiliki (baik itu tuntutan yang berasal dari individu maupun tuntutan berasal dari lingkungan) bersama segala cara yang mereka pakai di dalam menghadapi situasi stress (Smet, 1994).

\section{Kesimpulan}

Penelitian ini menguji apakah ada pengaruh dari dukungan sosial terhadap penyesuaian diri pada mahasiswa Sumatera di UIN Sayyid Ali Rahmatullah. Hasilnya memperlihatkan adanya dukungan sosial berpengaruh kepada penyesuaian diri pada mahasiswa Sumatera di UIN Sayyid Ali Rahmatullah. Mahasiswa Sumatera yang memiliki dukungan sosial yang tinggi maka akan memiliki penyesuaian diri yang tinggi pula, dan begitu sebaliknya.

\section{Saran}

Hasil dari penelitian memperlihatkan bahwa adanya pengaruh yang positif dari dukungan sosial terhadap penyesuaian diri pada mahasiswa rantau, agar bisa memperoleh penyesuaian diri yang tinggi maka mahaswa rantau harus memiliki dukungan soial yang baik. Dengan demikian, perlu dilakukan adalah dengan menumbuhkan kesadaran untuk meningkatkan dukungan sosial agar penyesuaian diri pada mahasiswa rantau juga meningkat 


\section{Daftar Pustaka}

Adawiyah, R. A. (2013). Kecerdasan Emosional, Dukungan Sosial dan Kecerdasan Burnout. Jurnal Psikologi. 2(2), 99-207.

Aprianti, A. (2012). Hubungan antara Parceived Social Support dan Psycological Well-being pada mahasiswa perantau tahun pertaman di Universitas Indonesia. (Unpublished Undergraduate's Thesis), Universitas Indonesia. Depok, Indonesia.

Aristya, D. N.,\& Rahayu, A. (2018). Hubungan Dukungan Sosial dan Konsep Diri dengan Penyesuaian Diri Remaja kelas X SMA Angkasa 1 Jakarta. Ikraith-Humaniora, 2(2).

Azwar, S. (1994). Seleksi aitem dalam penyusunan skala psikologi. Buletin Psikologi. 2(2), 26-33.

Baron, R. \& Byrne. (2003). Psikologi Sosial Edisi Keepuluh Jilid 2. Jakarta: Erlangga.

Chandra, P. E. (2004). Trik Bisnis menuju sukses. Yohyakarta: Grafika Indah.

Conley,C.S., Travers, L. V., \& Bryant, F.B. (2013). Promoting psychosocial adjustment and stress management in first-year college students: The benefits of engagment in a psychosocial in wellness seminar. Journal ofAmerican College Health, 61(2), 75-86.

Enung, F. (2008). Psikologi Perkembangan Peserta Didik. Bandung: Pustaka Setia.

Friedlander, L. J., Reid, G,J., Shupak, N., \& Cribbie, R. (2007). Social Support, Self-esteem, and Stress as Predictors of Adjustment to University Among First-year Undergraduates. Journal of College Student Development. 48(3), 259-274.

Gunarsa, D. Y. (2008). Psikologi Perkembangan Anak dan Remaja. Jakarta: Gunung Mulia.

Gerungan, A. (2004). Psikologi Sosial. Bandung: Rafika Aditama.

Halim, C.F.,\& Dariyo, A. (2016). Hubungan Psychological Well-being dengan Lonelinees pada mahasiswa yang merantau. Jurnal Psikogenesis. 4(2), 170181.http://doi.org/10.24854/ip.v4.344

Handayani, P., G.,\& Yuca., V. (2019). Kontribusi Culture Shock terhadap SelftAdjustment mahasiswa kelas Internasional Universitas Negeri Padang. Universitas Padang. Jurnal Neo Konseling. DOI:10.24036/00190kons2019 http://neon.ppj.unp.ac.id/index.php/neo

Hidayat, H., \& Handayani, P. G. (2018). Self Regulated Learning (Study for Students Regular and Training). Jurnal PenelitianBimbingan dan Konseling. 3(2), 50-59. http://.doi.org/10.30870/jpbk.v3il.3196

Heiman, T.,\& Kariv, D. (2005). Task-oriented versus emotion-oriented coping strategies: The case of college students. College Student Journal. 3(1), 72-89.

Khoyroh, I. (2016). Hubungan antara keterbukaan diri dengan penyesuaian diri mahasiswa Uin Maulana Ibrahim Malang yang menjalani Kuliah Kerja Mahasiswa (KKM) tematik Posdaya berbasis Masjid. Skripsi. Fakultas Psikologi. Universitas Islam Negeri Maulana Malik Ibrahim. Malang. 
Kementrian Riset, Teknologi, dan Pendidikan Tinggi. (2018) Laporan Tahunan. Diakses darihttps://www.brin.go.id/epustaka/laporan-tahunan-kemenristekdikti-2018/

King. A. L. (2012). Psikologi Umum (Sebuah Pandangan Apresiatif). Jakarta: Salemba Humanika.

Kumalasari, F.,\& Ahyani, L. N. (2012). Hubungan antara Dukungan Sosial dengan Penyesuaian Diri Remaja di Panti Asuhan. Jurnal Psikologi Pitutur. 1(1).

Kusrini\& Parihartani (2014). Hubungan Dukungan Sosial dan Kepercayaan Diri dengan Prestasi Bahasa Inggris Siswa Kelas VIII SMP Negeri 6 Boyolali. Jurnal Penelitian Humaniora. 5(2), (131-140).

Lestari, S. S.(2016). Hubungan keterbukaan diri dengan penyesuaian diri mahasiswa Riau di Yogyakarta. E-Jurnal Bimbingan dan Konseling. 3(5), 75-85.

Latuheru, M.E. (2014). Hubungan Kecerdasan Emosi dan Penyesuaian Diri pada siswa yang Tinggal dikost. Salatiga: Fakultas Psikologi Universitas Kristen Satya Wacana Salatiga. Skripsi Psikologi.

Lingga, R. W.,\& Tuapattinaja. J. M. (2012). Gambaran Virtue mahasiswa perantau. Predicara. 1(2), 6068.

Lee,. D. S.,\& Ybarra, O. (2017). Cultivating Effective Social Support Through Abstraction: Reframing Social Support Promotes Goals-Pursuit. Persinality and social Psychology Bulletin, Journal of SAGE Publication. $\quad$ (43), $2 . \quad 453-464$. DOI:10.1177/0146167216688http://journals.sagepub.com/doi/abs/10.1177/014616721773 $\underline{0371}$

Maharani, P. O.,\& Andayani, B. (2003). Hubungan antara Dukungan Sosial Ayah dengan Penyesuaian Sosial pada Remaja Laki-laki. Jurnal Psikologi. 1, 23-35.

Marta, S. (2014). Konstruksi makna budaya merantau dikalangan mahasiswa perantau. Jurnal Kajian Komunikasi. 2(1), 1-7).

Rahmat, J. (2005). Psikologi Komunikasi. Bandung: PT. Remaja Rosdakarya.

Riena. (2010). Hubungan antara Perilaku Coping dan Dukungan Sosial dengan Kecemas pada Mahasiswa skripsi. Journal ofPersonality and Social psycologi, 3(1).

Rufaida, H., \& Kustanti, E., R. (2017). Hubungan antara dukungan sosial teman sebaya dengan penyesuaian diri pada mahasiswa rantau dari Sumatera di Universitas Diponegoro. Jurnal Empati. 7(3).

Saniskoro, B. S. R., \& Akmal, S. Z. (2017). Peran Penyesuaian Diri di perguruan tinggi terhadap Stres akademik pada mahasiswa perantau di Jakarta. Jurnal Psikologi Ulayat. 4(1), 96. http://doi.org/10.24854.jpul2017-82

Santrock, J. W. (2006). Adolescence (Perkembangan Remaja) Terjemahan. Jakarta: Penerbit Erlangga.

Santrock, J. W. (2012). Perkembangan Masa Hidup. Edisi 5 Jilid 2. Jakarta: MeGraw-Hill Education.

Santrock, J. (2002). A topical approach to life-span development. Boston: McGraw-Hill. 
Sarafino, E., P. (2008). Health Psychology: Biopsychosocial Interactions Sixth Edition. USA: The College Of New Jersey.

Schneiders, A. (1964). Personal Adjusment and Mental Health. New York: Brosh Publishing Company.

Semiun, Y. (2006). Kesehatan Mental 1. Yogyakarta: Penerbit Kanisius.

Sharman, B. (2012). Adjusment and Emotional Mauturity Among First Year Collage Students. Pakistan Journal of Social and Clinical Psychology. 10(2), 32-37.

Smet,B. (1994). Psikologi Kesehatan. Jakarta: PT Grasindo.

Tazakhrofatin, D. (2018). Pengaruh Dukungan Sosial dan Orientasi masa depan terhadap Penyesuaian Diri. Psikoborneo. 6(4), 468-473.

Thurber, C. A., \& Walton, E. A. (2012). Homesicknees and Adjustment in University Students. Journal of American Colloge Health. 60(5), 1-5.

Tricahyani, I. A. R.,\& Widiasavitri, P. N.(2016). Hubungan antara Dukunga Sosial dengan Penyesuaian Diri pada Remaja Awal di Panti Asuhan Kota Denpasar. Jurnal Psikologi Udayana. 3(3).

Utami, M. S. (2012). Religiusitas, koping religius, dan kesejahteraan subjektif. Jurnal Psikologi, 39(1), 46-66. http://doi.org/10.22146/ipsi.6966.

Walgito, B. (2003). Pengantar Psikologi Umum. Yogyakarta: Yayasan Penerbitan Fakultas Psikologi UGM.

Walgito, B. (1994). Psikologi Sosial Suatu Pengantar. Yogyakarta: Fakultas Psikologi UGM.

Wijaya, O. B. (2015). Hubungan antara penyesuaian diri dengan kemandirian pada mahasiswa yang merantau fakultas Teknik Industri Universitas Bima Darma Angkasa 2014/2015 Palembang. Jurnal Psikologi Universitas Bina Darma Palembang. 1-14.

Wills, S., \& Sofyan. (2005). Remaja dan Masalahnya. Bandung: CV.Alfabeta. 